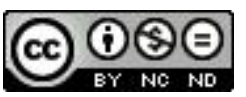

\title{
Leitura e Interpretação de Dados Prontos em um Ambiente de Modelagem e Tecnologias Digitais: o mosaico em movimento
}

\section{Reading and Interpreting ready data in an environment of modeling and digital technologies}

\author{
Leandro do Nascimento Diniz* \\ Marcelo de Carvalho Borba**
}

\begin{abstract}
Resumo
Neste artigo, analisamos a leitura e a interpretação de dados prontos coletados por alunos para desenvolverem projetos de modelagem. Consideramos dados prontos as informações coletadas na Internet, como um gráfico ou uma fórmula, sem maiores explicações de como foram geradas. Com isso, repensamos o mosaico de pesquisas do GPIMEM, grupo de pesquisa ao qual pertencemos e que desenvolve pesquisas sobre modelagem e informática há cerca de vinte anos. Na análise, privilegiamos a apresentação oral e o relatório escrito de um grupo de alunas do Curso de Ciências Biológicas da Universidade Estadual Paulista (UNESP). Os dados prontos sugerem uma nova faceta na relação entre tecnologias digitais e modelagem: eles parecem ser tratados de maneira idêntica a dados empíricos usualmente coletados em outros trabalhos de modelagem encontrados na literatura. Assim, o mosaico de pesquisas sobre o tema ganha novas dimensões na medida em que a Internet parece modificar a própria noção do que são dados.

\footnotetext{
* Mestre em Educação Matemática pela Universidade Estadual Paulista (UNESP). Membro associado do Grupo de Pesquisa em Informática, outras Mídias e Educação Matemática (GPIMEM). Membro do Grupo Educação Matemática em Foco (EMFoco) e do Grupo de Pesquisa Educação Matemática do Recôncavo da Bahia (GPEMAR). Docente do Curso de Licenciatura em Matemática da Universidade Federal do Recôncavo da Bahia (UFRB), Amargosa, BA, Brasil. Endereço para correspondência: Avenida Nestor de Melo Pita, 535, Centro, CEP: 45300-000, Amargosa, BA, Brasil. E-mail: leandro@ufrb.edu.br.

** Livre Docente pela Universidade Estadual Paulista (UNESP). Professor do Programa de PósGraduação em Educação Matemática da Universidade Estadual Paulista (UNESP) e coordenador do Grupo de Pesquisa em Informática, outras Midias e Educação Matemática (GPIMEM), Rio Claro, SP, Brasil. Endereço para correspondência: Departamento de Matemática - UNESP. Avenida 24A, 1515, Bela Vista, CEP: 13506-900, Rio Claro, SP, Brasil. E-mail: gpimem@rc.unesp.br.
} 
Palavras-chave: Educação Matemática. Tecnologias da Informação e Comunicação. Informática. Leitura e Interpretação de Gráficos Estatísticos. Ideologia da Certeza.

\begin{abstract}
In this paper, we analyze the reading and the interpretation of "ready data". We consider ready-data the information collected from the Internet, such as graphs or a mathematical formulas, without explanation of how they were generated. With this idea in mind, we rethink the mosaic of the research carried out by our research group, GPIMEM. This group has been conducting research on modeling and informatics for about 20 years. In the analysis, we focused on oral and written reports of a group of students from the Biological Science course at the State University of São Paulo (UNESP). The ready-data suggest a new facet in the relationship between digital technologies and modeling: they seem to be treated by students identically to the way they treat "empirical data" usually collected in other modeling projects, found in the literature. The mosaic of research about this theme acquires new dimensions since the Internet seems to modify the very notion of what data are.
\end{abstract}

Keywords: Mathematics Education. Information and Communication Technology. Informatics. Reading and Interpretation of Statistical Graphs. Ideology of Certainty.

\title{
1 Introdução
}

A pesquisa em modelagem tem sido objeto de frutíferas investigações, como demonstram os anais de congressos organizados pela Sociedade Brasileira de Educação Matemática (SBEM), além de inúmeras publicações sobre o tema. O mesmo pode ser dito sobre pesquisas acerca do uso de tecnologias digitais em educação matemática ${ }^{1}$. A sinergia entre estes dois temas já é um foco mais restrito.

Autores como Borba e Villarreal (2005) sintetizaram as investigações feitas no Brasil até aquele momento. Diniz (2007) desenvolveu a síntese feita e propôs variações críticas. Neste artigo, desenvolvemos um aspecto que emergiu na parte empírica de uma pesquisa, realizada pelos seus autores, num curso de Matemática Aplicada para alunos da Graduação em Ciências Biológicas.

Nessa disciplina, os alunos são convidados a escolher temas para desenvolver seus projetos de modelagem. Vários desses trabalhos serviram de base para as sínteses teóricas mencionadas acima e que serão detalhadas em seção posterior. Um exemplo, entretanto, traz um componente novo que ainda

\footnotetext{
${ }^{1}$ Para evitar repetições, consideramos como sinônimos: informática, Tecnologias da Informação e Comunicação, mídias informáticas e tecnologias digitais.
} 
não foi abordado. Um grupo de alunos - durante a apresentação oral de seus projetos de modelagem - comentou sobre um gráfico e uma fórmula (que encontraram na Internet) e justificaram que não sabiam como esses dados prontos - na fala de uma aluna - surgiram, isto é, como foram organizados.

Interpretamos dados prontos como sendo as informações coletadas na Internet, que já estão organizadas e que, nem sempre, trazem uma explicação sobre como foram coletadas e organizadas, por exemplo: um gráfico ou uma fórmula. Sintetizamos, afirmando que são modelos matemáticos os quais estão organizados de tal forma que buscam representar alguma informação, com a utilização da Matemática, sem maiores explicações sobre como foram constituídos.

Nossa intenção, neste artigo, é aprofundar as reflexões sobre esse aspecto, buscando compreender como os alunos utilizam os dados prontos coletados na Internet, ou seja, como eles os apresentam e os interpretam nos relatórios escritos e nas apresentações orais de projetos de modelagem. Interação, esta, que apresenta um aspecto não abordado pela literatura, dentro da sinergia entre modelagem e tecnologias digitais.

A análise foi feita a partir de dados coletados em investigações realizadas pelo Grupo de Pesquisa em Informática, outras Mídias e Educação Matemática (GPIMEM) $)^{2}$, que tem, desde 1993, modelagem matemática como um dos principais temas pesquisados. Membros do GPIMEM têm investigado as relações da modelagem com diferentes temas, como a avaliação (BORBA; MENEGHETTI; HERMINI, 1999a), a produção matemática desenvolvida pelos alunos (MALHEIROS, 2004), o processo da escolha de temas dos projetos de modelagem (HERMÍNIO, 2009) e as Tecnologias da Informação e Comunicação (TIC), com Ensino Presencial (ARAÚJO, 2002; DINIZ, 2007) e Educação a Distância (MALHEIROS, 2008; BORBA; MALHEIROS; ZULATTO, 2007).

Parte das pesquisas desenvolvidas pelo Grupo propicia um olhar integrado sobre modelagem, compreendida como uma Tendência da Educação Matemática que enfatiza uma estrutura curricular baseada em projetos, nos quais os alunos participam de seu desenvolvimento, sob a orientação do professor. Os olhares do GPIMEM se complementam, ou seja, buscam uma articulação em uma espécie de mosaico de investigações (ARAÚJO; BORBA, 2004; MALHEIROS; BORBA; DINIZ, 2005), no qual, metaforicamente, as diferentes pesquisas procuram preencher uma superfície plana ${ }^{3}$. Ao preencher essa região do plano,

\footnotetext{
${ }^{2}$ http://www.rc.unesp.br/gpimem/

${ }^{3}$ A metáfora usada possui limitações, pois há interseções nas pesquisas realizadas, o que não ocorre com as peças que formam um mosaico. Apesar disso, acreditamos que ela contribui para compreensão do que pretendemos abordar.
} 
novas questões são geradas, as quais podem ser compreendidas como possibilidades de se preencher outras regiões do plano, sob novos olhares, com novos focos de investigação. Esse continuum de pesquisas representaria, dentro dessa ideia, a possibilidade de expansão indefinida, assim como no plano.

Dessa forma, apresentamos neste artigo, de forma sucinta, a noção de modelagem, esclarecendo a nossa concepção. Em seguida, discutimos a visão de uso de informática que defendemos, em contraste com outras visões. Tal discussão está situada dentro de uma matriz construída por Borba e Villarreal (2005), assim como em atualizações da mesma, na qual são apresentadas diferentes visões do uso de TIC com distintas compreensões sobre modelagem. Discutimos, também, duas linhas de pesquisa da educação estatística na abordagem sobre a interpretação de gráficos, que identificamos como dados prontos e que foram coletados na Internet.

\section{A escolha do tema e os objetivos ao se propor atividades de modelagem}

Modelagem pode ser vista como um enfoque pedagógico em diversas práticas educacionais baseadas na ideia fundamental da Matemática Aplicada: dado um problema, procura-se um modelo matemático para descrever o fenômeno e se tenta realizar previsões. Por exemplo: se há um vazamento de óleo na costa brasileira, busca-se um modelo para estudar a dispersão do vazamento, tentando minimizar o desastre ecológico; se há uma epidemia como a AIDS, então, se criam modelos para compreender a maneira como o contágio tem acontecido, buscando-se a organização de políticas públicas para evitar uma pandemia. Poderíamos citar outros exemplos, mostrando que um modelo matemático, muitas vezes, se configura como uma ferramenta útil na compreensão de um fenômeno.

Existem algumas variações em relação à maneira como a modelagem é utilizada como estratégia pedagógica. Uma primeira possibilidade é utilizá-la como ferramenta para ensinar um conteúdo matemático específico. Assim, a escolha do tema para o projeto de modelagem está diretamente relacionada ao conteúdo que se quer ensinar. Por exemplo, um professor pode escolher um tema para garantir um debate político nas aulas de Matemática, como lixo, e poderão ser debatidas a questão ambiental e as relações sociais envolvidas no movimento que tem sido conhecido como educação matemática crítica. Portanto, nesta primeira possibilidade, a escolha pelo tema fica, essencialmente, a cargo do professor. 
Uma segunda possibilidade, que defendemos, seria deixar a escolha do tema a critério dos alunos ${ }^{4}$. A princípio, poderíamos pensar que os alunos estariam mais engajados no desenvolvimento do projeto de modelagem. Pesquisas realizadas pelo GPIMEM associaram o interesse do aluno na escolha do tema como sendo um importante fator que influencia sua participação (HERMÍNIO, 2009). Entretanto, eles podem não se engajar tanto como se pode imaginar, já que a escolha do tema pode ser feita para agradar ao professor, pois os alunos já preveem, desde o início, que conteúdos matemáticos seriam abordados. Neste caso, o projeto de modelagem pode desembocar em um tópico matemático, previsto ou não, mas também pode contemplar uma agenda social, ambiental, política, entre outras. Pode ser, também, uma combinação dessas possibilidades.

No GPIMEM, também existe uma perspectiva de modelagem em que o uso de software e o estudo de determinado conteúdo matemático já estão garantidos, na medida em que um tema já é apresentado em um laboratório de informática, como uma problemática que conduz o aluno para o uso das TIC e com uma abordagem matemática de um tema a ser explorado. Por exemplo, Javaroni (2007) discute abordagens geométricas das equações diferenciais para analisar modelos matemáticos. Já o trabalho de Soares (2010) utiliza um tema biológico - Transmissão da Malária - como tema motriz para que os alunos, como parte do coletivo de seres-humanos-com-software-modellus, compreendam a dinâmica do processo de transmissão da doença. Neste processo, o professor dialoga com os estudantes, utilizando conceitos como função, taxa de variação e derivada.

Entendemos, a partir das considerações feitas, que a escolha do tema é um dos aspectos que está diretamente relacionado aos objetivos do professor quando propõe uma atividade de modelagem. O GPIMEM não é monolítico em suas visões sobre modelagem. As pesquisas no Grupo já foram desenvolvidas com a escolha do tema sendo feita pelo professor ou pelos alunos. Além disso, no parágrafo anterior, ressaltamos que as concepções da tecnologia podem influenciar os objetivos que se tem ao propor atividades de modelagem. De todo modo, analisamos, mais a frente, como esta discussão interage com aquela sobre o uso de TIC, e da Internet em particular. Antes, porém, apresentamos uma forma de compreender como os seres humanos interagem com as TIC.

\footnotetext{
${ }^{4} \mathrm{O}$ primeiro autor do artigo também sustenta que o professor pode escolher o tema, considerando que possa despertar a curiosidade dos alunos, uma vez que pode perceber quais temas eles teriam desejo de saber mais.
} 


\section{Seres-humanos-com-mídias e concepção de tecnologia em Educação Matemática}

Lévy (1993) destaca a presença das mídias na história da humanidade: oralidade, escrita e informática, considerando-as como tecnologias da inteligência. Ele afirma que estão associadas à produção de conhecimento e à memória.

Quando pensamos em Matemática, o fazemos em conjunto com uma mídia. Seres humanos que utilizam um software gráfico, por exemplo, passam a pensar com ele, mesmo se não estiverem diretamente em contato visual com a tela do computador. A experiência de fazer testes, que relacionam expressões analíticas de funções e gráficos, impregna o que os sujeitos cognoscentes conhecem e fazem para buscar uma dada tecnologia para resolver um problema. Estudantes podem pensar numa atividade enquanto caminham, mas que realizaram com o software, sugerindo que as mídias estão nos sujeitos cognitivos (LÉVY, 1993), ou seja, os seres humanos podem pensar com o computador (BORBA; VILLARREAL, 2005). As mídias também conectam os seres humanos, estando entre eles, como um nó na rede que une, estrutura o coletivo e possibilita a comunicação (LÉVY, 1993).

Por outro lado, seres humanos desenvolvem software, criam novas interfaces e novas mídias informáticas, atualizam sítios da Internet, enfim, moldam as TIC, assim como também são moldados por elas. Como ilustrado no exemplo acima, o computador, que foi desenvolvido por humanos, também molda os que o utilizam para realizar investigações.

Por isso, quando os seres humanos pensam, não apenas eles pensam, ou seja, "O pensamento já é sempre a realização de um coletivo" (LÉVY, 1993, p. 169, grifo do autor). No coletivo, os seres humanos estão pensando com escrita, métodos, regras, compasso etc. Para escrever o que está sendo lido agora, este texto foi pensado com escrita, o software Word, livros, Internet etc., num processo não linear para produção de conhecimento. Villarreal e Borba (2010) documentam que, ao longo da história da Matemática, artefatos culturais ou materiais foram utilizados para produção da Matemática. Diferentes artefatos, linguagens e as TIC têm, portanto, reorganizado a forma como pensamos.

Visando enfatizar o fato de que o conhecimento é intrinsecamente ligado a humanos e mídias, Borba e Villarreal (2005) propõem a noção de que o conhecimento é produzido por coletivos de seres-humanos-com-mídias. Humanos necessitam de tecnologias da inteligência-oralidade, escrita e as novas linguagens multimodais e processos de simulação que impregnam as mídias informáticas para produzirem conhecimento.

Nesse contexto, o pensamento coletivo pode ser reorganizado, a partir 
de um feedback proporcionado pelas TIC, mediante uma ação realizada pelo coletivo. Com isso, adotamos a noção de reorganização do pensamento proposta por Tikhomirov (1981), o qual analisou como os computadores afetam a cognição humana e, em consequência, afetam a Educação. Computadores não substituem humanos. Eles são tecnologias impregnadas de humanidade, da mesma forma que ajudam a constituir os seres humanos que a utilizam. Dessa forma, Tikhomirov (1981), discípulo de Vygotsky, propõe que o computador é, qualitativamente, distinto da linguagem devido aos processos de simulação e de extensão mnemônicos. Tal consideração passa a ter novas possibilidades com o desenvolvimento da informática, a qual realçou os discursos multimodais como forma de expressão e conhecimento.

Nesta perspectiva, as mídias são co-partícipes na produção de conhecimento e, como argumentaremos, interagem e modificam a estratégia pedagógica, denominada modelagem, que é utilizada por estudantes e professores dentro e fora da sala de aula.

\section{Um mosaico de pesquisas que utilizam informática em modelagem}

Baseados nas considerações sobre informática e conhecimento, expostas anteriormente, de modo geral, membros do GPIMEM pesquisam exemplos que sugerem "pedagogias que se harmonizam com as mídias informáticas de modo a aproveitar as vantagens de suas potencialidades." (BORBA; PENTEADO, 2007, p. 44). Uma síntese provisória das possibilidades de interação entre TIC e modelagem foi desenvolvida por Borba e Villarreal (2005) e, posteriormente, modificada por Diniz (2007) na forma da matriz abaixo.

\begin{tabular}{|c|c|c|c|c|c|}
\hline $\mathrm{C}_{\text {Modelagem }}^{\text {TIC }}$ & Tutorial & Motivação & \multicolumn{2}{|c|}{ Reorganização } & Cidadania \\
\hline $\begin{array}{l}\text { Problema Aplicado no } \\
\text { Livro Didático Tradicional }\end{array}$ & A & & & & \\
\hline Tópico Matemático & & B & \multirow{3}{*}{ 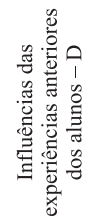 } & & \\
\hline $\begin{array}{l}\text { Situação-problema de } \\
\text { Modelagem posta pelo } \\
\text { professor }\end{array}$ & & & & $\mathrm{E}$ & G \\
\hline Projetos de Modelagem & & $\mathrm{C}$ & & $\mathrm{F}$ & $\mathrm{H}$ \\
\hline
\end{tabular}

Matriz 1 - Adaptação de Borba e Villarreal (2005, p. 58) das diferentes perspectivas considerando modelagem e TIC na Educação Matemática

(DINIZ, 2007, p. 27). 
No momento em que essa matriz foi inicialmente desenvolvida, os software Excel e Winplot eram bastante utilizados, ao lado das calculadoras gráficas, que podem ser pensadas de forma isomorfa aos software de funções. A célula A combina a perspectiva de modelagem problema aplicado no livro didático tradicional com o uso tutorial das TIC. Atividades de modelagem podem ser propostas utilizando software que possuem um conjunto de instruções com pouca interação com os alunos, pois são pensados de modo semelhante ao paradigma do exercício ${ }^{5}$. Borba e Villarreal (2005) afirmam que esse tipo de atividade de modelagem possui limitações, pois mantém a lógica da proposição do problema de não contar com a participação do estudante. Além disso, do ponto de vista da informática, a nova mídia serviria apenas para ampliar, de forma limitada, o que já é feito com auxílio da mídia lápis-e-papel. Alguns livros didáticos que incorporaram o apoio de software com exercícios aplicados seriam exemplos dessa célula.

Outra perspectiva de modelagem foca no tópico matemático, em que as atividades de modelagem são combinadas com o uso das TIC, vistas como motivação (célula B), com o objetivo principal de criar condições para que conteúdos matemáticos possam ser ensinados e aprendidos. Entretanto, Borba e Villarreal (2005) destacam que, para manter a motivação por um longo período, é necessário um vultoso investimento, com novidades tecnológicas incessantemente sendo apresentadas aos estudantes. Mais ainda, não há pesquisas sugerindo que a motivação se mantenha após um momento inicial.

A célula $\mathrm{C}$ combina as perspectivas projetos de modelagem com a motivação do uso das TIC. Assim, professores podem convidar os alunos a escolherem temas e, com a utilização de diversas TIC, os manteriam motivados. Conforme é discutido em Borba e Villarreal (2005), esse interesse pela informática ou pelo tema do projeto pode ser duradouro, ou efêmero, por motivos que só posteriormente foram analisados por Hermínio (2009).

A célula $\mathrm{D}$ pode ser associada à pesquisa de Araújo (2002). Um professor de Cálculo convidou os alunos para desenvolverem um projeto de modelagem, com objetivo de criar condições para que aprendessem conteúdos matemáticos. Além disso, sugeriu que os alunos utilizassem um software matemático, para motivá-los. Por sua vez, os alunos inventaram dados que, supostamente, seriam modelos matemáticos prototípicos do tema. A autora identifica como as experiências vivenciadas nas escolas influenciaram os alunos, pois, geralmente,

\footnotetext{
${ }^{5}$ No paradigma do exercício, o professor segue a sequência definição, exemplos e exercícios na sua prática de sala de aula.
} 
resolvem problemas fictícios presentes em livros didáticos, buscando satisfazer o professor. Recentemente, Hermínio (2009) e Hermínio e Borba (2010) discutiram, também, como o interesse pode se converter em interesse para agradar o professor.

As células E e F representam atividades nas quais a informática é proposta para reorganizar o pensamento, conforme apresentado na seção anterior. $\mathrm{O}$ que as diferencia é o tipo de atividade, em que o professor pode compartilhar a responsabilidade pelo desenvolvimento da atividade com o aluno (BARBOSA, 2001) com menor intensidade, quando temos a situação-problema posta pelo professor ou, com maior, quando temos projetos de modelagem.

Algumas pesquisas do GPIMEM envolvem modelagem e uso de softwares para construção de gráficos. Araújo (2002), Malheiros (2004), Borba e Penteado (2007) e Diniz (2007) discutem exemplos nos quais alunos utilizam software nas construções de gráficos estatísticos e de funções. Essa investigação pode ser feita usando o comando adicionar linha de tendência do Excel ou fazer o ajuste de curva, usando o enfoque experimental-com-tecnologia. Borba e Penteado (2007) analisam um exemplo no qual o ajuste de curva é feito por uma função quadrática, mas, para melhorá-lo, os alunos modificaram valores dos coeficientes para realizarem deslocamentos verticais e/ou horizontais ou abrirem a concavidade, ou seja, movimentaram o gráfico para que pudessem representar melhor a situação investigada. Assim, para encontrar esses gráficos, os alunos podem utilizar a simulação e a previsão (DINIZ, 2007), pois gráficos podem ser construídos a partir de dados iniciais coletados (em experimentos, em livros e/ou na Internet) e alguns procedimentos são feitos para que sejam encontrados novos valores, ajustando os pontos inseridos numa curva (EDWARDS; HANSOM, 1990). A simulação possibilita "a capacidade de variar com facilidade parâmetros de um modelo e observar imediata e visualmente as consequiências dessa variação constitui uma verdadeira ampliação da imaginação." (LÉVY, 2000, p. 166). Diniz (2007) apresenta alguns tipos de simulações que geraram diferentes possibilidades para as previsões.

Na matriz apresentada, Borba e Villarreal (2005) nomeiam a última perspectiva do uso das mídias informáticas de cidadania, pois defendem o direito e a democratização do acesso à informática. Atualmente, é fácil termos lan houses em comunidades, com preço acessível, o que possibilita um acesso maior das pessoas. Inclusive, há regiões no país onde a Internet sem fio está disponível gratuitamente, basta que tenhamos a placa de rede para conectar. Atividades de modelagem podem ser contempladas nas células G e H como 
forma de criar condições para que esta vertente da cidadania seja exercida.

Pesquisas sobre a interação entre TIC e modelagem têm sido feitas no GPIMEM, de forma intensa, nas salas de aula da disciplina Matemática Aplicada, do Curso de Ciências Biológicas, ministrada pelo segundo autor deste artigo, desde 1993 (DINIZ, 2007; BORBA; VILLARREAL, 2005). De modo geral, trabalha-se a noção de modelagem com os alunos organizados em grupos, e que são convidados a escolherem um tema para investigação. O professor interage com os grupos de alunos, buscando o desenvolvimento do projeto de modelagem, o qual é apresentado oralmente e por escrito. Cursos de extensão (BARBOSA, 2001; JAVARONI, 2007) ou salas de aula em outras instituições (ARAÚJO, 2002) também têm sido utilizados como ambiente para desenvolvimento de diferentes pesquisas.

Assim, a interação TIC - Modelagem tem sido uma característica marcante do GPIMEM. Ao olharmos para fora de nosso grupo, encontramos poucos artigos que abordam modelagem e TIC e, muitas vezes, o fazem apenas de maneira genérica. Por exemplo, Blum e Niss (1991) pontuavam que o uso de computadores em atividades de modelagem agiliza cálculos e permite lidar com situações complexas e reais, a variação de parâmetros e as simulações.

Numa busca realizada em anais de três importantes Encontros ${ }^{6}$, dois nacionais: Conferência Nacional sobre Modelagem na Educação Matemática (2007 e 2009) e Encontro Nacional de Educação Matemática (2007 e 2010); e um internacional: Simpósio Internacional de Pesquisa em Educação Matemática (2006 e 2009), encontramos apenas três artigos que não são de membros do GPIMEM - o que ressalta a baixa produção de pesquisas realizadas fora do Grupo.

Ferreira e Burak (2009) tecem considerações sobre um curso online de modelagem, oferecido para professores de escolas públicas do Paraná. Com o uso do ambiente virtual, os autores destacam a importância da interação, no sentido de compartilhar dificuldades e experiências desenvolvidas. Este artigo não enfatiza a sinergia entre cursos online e projetos de modelagem.

Silva e Levy (2009) destacam que é inevitável, apesar de complexo, não pensar modelagem e TIC conjuntamente. Eles utilizam um exemplo de atividade que pode ser realizada no paradigma definição, exemplo e exercício, ou numa perspectiva que defendem, abordando “[...] o equilíbrio e a conexão dos diversos conhecimentos em sua globalidade, possibilitando ao educando uma formação holística que leve em consideração as partes, as suas interligações e a(s)

\footnotetext{
${ }^{6}$ Consideramos os dois últimos Encontros realizados até o momento da escrita do artigo.
} 
totalidade(s)" (SILVA; LEVY, 2009, p. 11), numa abordagem sociopolítica, a qual é baseada em Skovsmose. Os autores destacam a possibilidade de conectar vários conhecimentos, a partir da busca de informações que estão disponíveis na Internet. Assim, é possível ver que a interação entre essas duas tendências se expande a outras, como a educação matemática crítica.

Santos e Almeida (2007) tiveram como objetivo refletir sobre o uso de software no ambiente de modelagem. Os alunos da licenciatura em Matemática, utilizando conteúdos de Cálculo Diferencial e Integral, encontraram a área de um terreno com lápis-e-papel. Na semana seguinte, eles reconstruíram o processo realizado, só que utilizando o software Modellus.

Enfatizamos a interação entre algumas facetas das TIC, particularmente da Internet, e das pesquisas em modelagem, sintetizada na matriz. Os olhares atuais de membros do GPIMEM partem e amplificam os exemplos vinculados às células $\mathrm{F}$ e $\mathrm{H}$ (combinação entre projetos de modelagem com reorganização e cidadania, respectivamente).

A matriz foi confeccionada sob forte influência de software de funções usados nos projetos de modelagem, com base em cerca de vinte anos de pesquisa. Não foi levada em consideração, de forma central, a força que a Internet passou a ter não só nas práticas educativas, mas no cotidiano em geral. Se os dados coletados na Internet já eram importantes para os trabalhos de modelagem, no início da década passada, eles se tornam ainda mais importantes devido ao crescimento da oferta de banco de dados. Posteriormente, analisamos como isto se conecta com a educação estatística. Antes, porém, abordamos como os dados prontos foram coletados na grande rede.

\section{Modelagem e a coleta de dados na Internet}

Com o acesso à Internet, desde o final do século passado, mas, definitivamente, nos últimos cinco anos, novas alternativas surgiram para que ela viesse a participar de coletivos de seres-humanos-com-mídias que desenvolvem projetos de modelagem.

A Internet pode ser considerada como uma espécie de biblioteca virtual, na qual se pode procurar por informações de um tema qualquer. No que tange à Educação, seu uso possibilita interação, comunicação, publicação de materiais e acesso à informação (KALINKE, 2003).

Atualmente, é muito comum começarmos as buscas de informações sobre um tema, utilizando sítios de busca. Entretanto, como realizá-las? Que 
palavras-chave digitar? Como identificá-las? Quando os alunos buscam informações na Internet e as selecionam, têm que considerar vários aspectos, como: descobrir relações não imaginadas, analisar enfoques diferenciados, qual parte selecionar para uso no trabalho e o que será aprofundado, dentre outros aspectos (MAGDALENA; COSTA, 2003). Talvez, o desafio maior seja produzir um texto, ou seja, um relatório da pesquisa desenvolvida, superando o copiarcolar, tão fácil de ser feito, com a Internet e os editores de texto, avançando para a autoria.

Reunir essas informações e produzir algo próprio, ser autor, é o próximo desafio! Isso implica em, a partir do recolhido, fazer um esforço de compreensão do material lido, tentando compartilhar e/ou harmonizar os fragmentos de textos ou informações selecionadas coordenando-as em um todo coerente e original. (MAGDALENA; COSTA, 2003, p. 55).

Temos a possibilidade de desenvolver propostas que envolvam coleta de informações na Internet em trabalhos de modelagem realizados com alunos, reunidos em grupos, pesquisando sobre temas atuais que ainda não podem ser encontrados em livros. Nesse caso, o professor pode oferecer possibilidades para que os alunos contribuam com o currículo ${ }^{7}$, pois eles podem trazer informações para serem discutidas na sala de aula (BORBA; VILLARREAL, 2005).

Com a presença cada vez mais ubíqua da Internet, exercícios podem ser facilmente resolvidos, como construir o gráfico de uma função quadrática. Os alunos podem buscar o gráfico já construído na Internet ou inserir os coeficientes num sítio que possua um objeto de aprendizagem da função quadrática ${ }^{8}$.

Em artigo publicado após a elaboração da matriz apresentada anteriormente, Borba (2009) propõe uma reflexão mais radical em relação à presença da Internet na sala de aula, através da seguinte pergunta: que tipos de questões se tornariam problemas, considerando salas de aula de Matemática em que o acesso à Internet é irrestrito? O autor destaca que, para mostrar sua perspectiva relativista sobre a noção de problema, "o que é percebido como um

\footnotetext{
${ }^{7}$ Neste artigo vamos tomar a noção de currículo a partir de uma adaptação da noção de currículo de Freire, que pode ser entendida como "a política, a teoria e a prática do que-fazer na educação, no espaço escolar, e nas ações que acontecem fora desse espaço." (STRECK; REDIN; ZITKOSKI, 2009, p. 109). Entendemos que a modelagem é a expressão de uma perspectiva dialógica de currículo, com espaço para as vozes do aluno e da comunidade sobre o que deve ser feito na educação escolar. ${ }^{8}$ Por exemplo: http://www.wolframalpha.com.
} 
obstáculo, o que provoca interesse, depende da mídia disponível” (BORBA, 2009, p. 458, tradução nossa). Assim, se a Internet for aceita na sala de aula, as noções de interesse e problema estarão em transformação. Ser aceita implica em acesso a ela em todas as práticas de sala de aula, inclusive nas avaliações, de forma semelhante àquela que qualquer professor, utilizando ou não modelagem, lida com outra tecnologia, como o relógio, que é aceito nas práticas educacionais.

De toda forma, enquanto não temos consolidada esta sala de aula permeada pela Internet, os alunos de graduação, em seus trabalhos, já utilizam mais webgrafias ${ }^{9}$ do que bibliografias. Em particular, ao invés de coletar dados, uma tradição dos trabalhos de modelagem em educação matemática, nos últimos cinco anos, há grupos que preferem utilizar informações armazenadas em bancos de dados, cada vez mais presentes na grande rede. Identificamos que parte dos dados coletados é estatístico.

\section{Os projetos de modelagem, os gráficos estatísticos e a educação estatística}

Nos projetos de modelagem, os alunos são convidados, a partir da escolha dos temas, a coletarem informações qualitativas e quantitativas. É comum notarmos a presença de dados estatísticos. Uma possível justificativa para essa presença é a necessidade do aluno agradar o professor (HERMÍNIO, 2009). Uma explicação alternativa é que a estatística se presta a projetos, como afirmam Campos, Wodewotzki e Jacobini (2011) num livro, em que discutem a sinergia entre educação estatística, modelagem e educação matemática crítica.

Embora a sinergia entre tendências, neste artigo, seja entre modelagem e o uso de tecnologias digitais em educação matemática, o trabalho com estatística se constituiu uma porta aberta para que temas como ideologia da certeza (BORBA; SKOVSMOSE, 2001) emergissem, como no exemplo que será apresentado. Ideologia da certeza deve ser entendida como o conjunto de ideias que enfatiza que um argumento numérico, estatístico, ou matemático, de um modo geral, deve ser necessariamente privilegiado em relação a outros. Os números são - nesta perspectiva, que permeia boa parte de nossa sociedade superiores a argumentos que não são quantificados. A ideologia da certeza pode ser, portanto, uma terceira vertente para se explicar porque os alunos utilizam estatísticas com maior intensidade em seus projetos de modelagem.

Com isso, tem se tornado frequente o uso de dados prontos, coletados

9 Referências coletadas na Internet. 
diretamente da Internet, e, desta constatação, surge nossa pergunta: como os alunos os interpretam?

$\mathrm{Na}$ literatura sobre educação estatística, identificamos duas linhas de pesquisa sobre como os estudantes interpretam as representações gráficas. Curcio (1987) considera importantes os conhecimentos prévios dos alunos para interpretar e generalizar os dados. Ele destaca que os estudantes têm conhecimentos prévios da representação, como identificar título, variáveis dos eixos e termos usados como essenciais para compreendermos as relações matemáticas expressas nos gráficos; conteúdos matemáticos abordados, como os conceitos numéricos e operações básicas; e o tipo de gráfico, como o de linha, pictórico e de barras, os quais são fundamentais para realizar as interpretações.

Outra linha de pesquisa enfatiza aspectos socioculturais, visão que sustenta uma crítica a Curcio (1987), mostrando que ele foca apenas conhecimentos técnicos para a interpretação dos gráficos "[...] e investiga tipos de gráficos tradicionalmente usados nas escolas, os quais têm proposições pedagógicas limitadas em termos de comunicação de dados. Curcio não considera aspectos do contexto relacionado à interpretação daqueles gráficos" (CARVALHO; MONTEIRO; CAMPOS, 2010, p. 221). Monteiro (2006, p. 2) acrescenta que os alunos podem aceitar "[...] de maneira passiva as principais ideias apresentadas".

Por outro lado, não identificamos, na visão sociocultural, uma alternativa a Curcio (1987), no tocante à análise dos gráficos estatísticos. Neste artigo, pretendemos, também, estabelecer uma conexão entre o clássico trabalho de Curcio (1987) e a perspectiva sociocultural.

Curcio (1987) classifica a compreensão de um gráfico em três níveis: ler os dados, ler entre os dados e ler além dos dados. No primeiro nível, ler os dados, há apenas uma leitura de informações que estão presentes num gráfico, como identificar um ponto pertencente ao gráfico. Não é solicitado nenhum tipo de interpretação.

No segundo nível, ler entre os dados, é necessário utilizar conceitos matemáticos para realizar cálculos, ou seja, o aluno analisa as informações presentes no gráfico e realiza cálculos. De modo geral, os dois primeiros níveis são mais comumente encontrados em atividades presentes nos livros didáticos.

No nível ler além dos dados, espera-se que o aluno reflita sobre os dados, projete-os para o futuro e busque conhecimentos prévios sobre o assunto apresentado no gráfico. Com isso, os estudantes precisam mobilizar esses 
conhecimentos, pois não há, explicitamente, todas as informações no gráfico para responder às questões propostas.

Gomes, Carvalho e Monteiro (2011) identificaram na literatura diferentes níveis de informação a ser analisada pelos estudantes num gráfico: informações locais, como a leitura de um ponto do gráfico, interpolações, como na análise de dados (discretos) coletados e na identificação de um padrão para prever novos valores, e informações globais, como na análise da variabilidade, ou seja, "a maior ou menor diversificação dos valores de uma variável em torno de um valor de tendência central [como a mediana, média aritmética e moda] tomado como ponto de comparação" (CRESPO, 2001, p. 109).

Numa pesquisa desenvolvida sobre a dificuldade dos alunos em interpretar os gráficos, Fernandes e Morais (2011) pontuam que não há diferenças significativas quanto aos acertos dos estudantes às respostas dos gráficos de linhas, barras e setores, sendo que, em cada questão, perguntas dos três níveis propostos por Curcio (1987) foram feitas. Entretanto, focando apenas o nível ler além dos dados, os autores identificaram que, numa questão envolvendo conteúdos abordados na escola, houve maior número de acertos do que em outra questão, a qual não os possuía, o que reforça a importância do contexto sociocultural na interpretação.

Podemos articular a leitura com a reflexão, pois o estudante é convidado a se posicionar diante das informações e, a partir disso, ter novas compreensões. "Ler é um ato de conhecimento, uma ação de compreender, transformar e interpretar o que o texto escrito apresenta." (SMOLE; DINIZ, 2001, p. 70). E, segundo as autoras, a capacidade de ler os gráficos e tabelas deve ser considerada no sentido de formar o leitor nas aulas de Matemática.

A ênfase em leitura está em sintonia com as ideias de Curcio (1987) sobre interpretação de gráficos. Então, neste artigo, utilizaremos a discussão sobre distintas formas de se interpretar ou ler um gráfico, embora deixemos de lado a noção de nível, na medida em que entendemos que não há necessariamente esta hierarquia no caminho percorrido por diferentes estudantes.

\section{A leitura e interpretação de dados prontos coletados na Internet}

A análise, aqui proposta, foi realizada a partir dos projetos de modelagem de uma turma do Curso de Ciências Biológicas, no contexto das atividades da disciplina de Matemática Aplicada, na qual os conteúdos função, derivada e integral são abordados, utilizando estratégias pedagógicas como experimental- 
com-tecnologia, projetos de modelagem e exposição de conteúdos. Coletamos dados a partir da filmagem e do armazenamento de trabalhos de alunos, incluindo as apresentações orais, e da realização de entrevistas. O tema dos projetos de modelagem foi escolhido pelos estudantes.

Diferentes pesquisadores investigam aspectos que emergem dos dados de formas distintas (BOGDAN; BIKLEN, 1994; ARAÚJO; BORBA, 2004). Diniz (2007), por exemplo, foca na interação entre TIC e modelagem. Um dos grupos, formado pelas alunas Érica, Joice, Luciana e Luciane, escolheu o tema Câncer de Próstata. Deste projeto de modelagem emergiu a questão central deste artigo.

Uma aluna do projeto Câncer de Próstata utilizou a expressão dados prontos para destacar uma fórmula, a qual foi coletada no sítio do Instituto Nacional do Câncer (INCA), principal referência usada pelo grupo. Ela afirmou que não havia explicação sobre como a fórmula surgiu, apenas estava pronta. Essa informação era difícil de ser conseguida, pois se referia a uma pesquisa publicada num livro em inglês, e os dados dos Estados brasileiros não estavam disponíveis em livros, já que o projeto de modelagem foi desenvolvido no primeiro semestre de 2005, ano a que os dados se referiam, não tendo, portanto, tempo útil para que as publicações estivessem disponíveis.

\subsection{Uma escala meio complicada}

As alunas fizeram uma apresentação oral de cerca de vinte minutos e o professor solicitou que apresentassem um gráfico que estava no relatório escrito, previamente lido pelo professor, mas que não estava presente nos slides exibidos. Elas apresentaram o gráfico e o quadro abaixo (Figura 1).

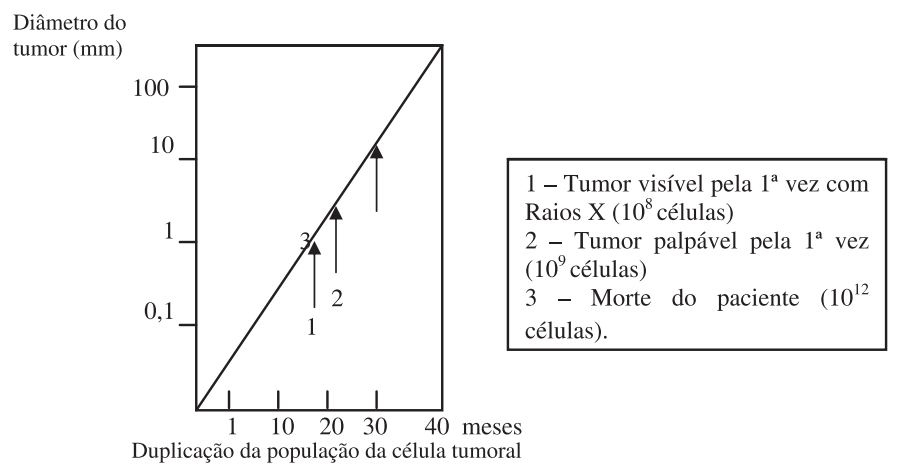

Figura 1 - Duplicação da célula tumoral em função do tempo (relatório escrito) 
Joice: Esse gráfico... aqui é o tamanho do tumor (apontando para o eixo vertical) e aqui é [...] o [tempo em] meses (apontando para o eixo horizontal) e ele é traçado em uma escala logarítmica, é uma coisa meio complicada, eu não consegui entender muito bem [...]. O tumor é uma coisa muito pequena [...]. Quando você consegue detectar, ele tá com $10^{9}$ células, uma coisa assim muito pequena. Então, o paciente tá morrendo, [...] o tumor tá com três centímetros [de diâmetro] [...].

Luciana: [...] Talvez, no futuro, ele mude assim essa subida tão rápida com a morte das pessoas porque já tem uma pesquisa para diminuir a duplicação das células tumorais que se multiplicam muito rápido, muito mais do que as células normais, então as proteínas que "imunizem essa multiplicação" e aí o tumor não cresce tanto.

Notamos que Joice lê o gráfico e reflete sobre os números, que são potências de 10, mas que representam algo pequeno, quando comparado a um objeto que pode ser manuseado, comparando-o com o tamanho do diâmetro. Acreditamos que o contexto da apresentação oral não favoreceu que elas apresentassem o gráfico, já que não o entenderam, mas admiramos a ousadia delas em colocá-lo na versão escrita entregue ao professor uma semana antes da apresentação oral.

O professor percebeu que as alunas do grupo tiveram pouco êxito, pois elas não conseguiram explorar o gráfico como poderiam, já que tinham informações para isto. O professor propôs, e acreditamos que a situação mostrouse adequada para gerar conhecimento novo sobre gráficos. Ele foi ao quadro e explicou que, na escala comumente usada, o gráfico ficaria muito próximo ao eixo y, pois cresceria muito rápido, o que dificultaria a visualização.

Assim, o não conhecimento das alunas quanto à escala do gráfico criou dificuldades para compreensão e interpretação. As alunas estavam, na linguagem de Curcio (1987), lendo os gráficos, mostrando que tal leitura é algo complexo.

\subsection{Pictograma e uma fórmula simples}

O grupo apresentou um pictograma (mapa do Brasil) com as estimativas de câncer de próstata para 2005, para cada cem mil homens, por Estado. A aluna Luciane destacou que, de modo geral, os valores mais baixos estavam situados na Região Norte do país (menor valor: 13,1 - Maranhão $)^{10}$ e os mais

\footnotetext{
${ }^{10}$ Apesar de pertencer à região Nordeste, o Maranhão faz divisa com dois estados da Região Norte: Pará e Tocantins, inclusive a estimativa do Pará é 16,11, a segunda menor do gráfico.
} 
altos, na Região Sul (maior valor: 83,48 - Rio Grande do Sul (RS)). As alunas levantaram uma conjectura para justificar o valor do RS: fatores alimentares, devido à alta ingestão de carne. O levantamento de conjecturas foi influenciado, possivelmente, pelo contexto experimental-com-tecnologias, o qual o professor propôs nas aulas que envolviam conteúdos matemáticos (BORBA; VILLARREAL, 2005). Neste enfoque, os alunos são estimulados a gerar conjecturas através de problemas abertos desenhados para serem desenvolvidos por coletivos de seres-humanos-com-TIC. Quanto ao gráfico, as alunas fizeram a leitura dos dados e buscaram situações que envolviam experiências anteriores em sala de aula para levantarem hipóteses que poderiam explicar os valores, ou seja, buscaram fazer a leitura além dos dados (CURCIO, 1987), com o olhar do seu contexto sociocultural.

Em seguida, o grupo apresentou uma fórmula utilizada para estimar o número de casos novos, presentes no gráfico pictórico: $\mathrm{TI}_{\mathrm{L}}=\mathrm{TM}_{\mathrm{L}} \times\left(\mathrm{I}_{\mathrm{R}} / \mathrm{M}_{\mathrm{O}}\right)$, em que $\mathrm{TI}_{\mathrm{L}}$ é a taxa de incidência estimada para a Unidade da Federação ou capital; $\mathrm{TM}_{\mathrm{L}}$ é a taxa de mortalidade estimada pela série histórica de mortalidade para a Unidade da Federação ou capital; $I_{R}$ é o número de casos novos do Registro de Câncer de Base Populacional (RCBP) (período entre 1996 e 2000); e $\mathrm{M}_{\mathrm{O}}$ é o número de óbitos das localidades onde existem RCBP (período entre 1996 e 2000) obtidos no Sistema de Informação sobre Mortalidade ${ }^{11}$.

As alunas fizeram apenas a leitura das informações presentes. $\mathrm{O}$ professor Marcelo Borba fomentou o debate para que elas pudessem ler entre os dados. Para isso, pediu que mostrassem um exemplo de como o cálculo foi feito para o RS, chutando valores. As alunas apresentaram o seguinte exemplo no quadro negro:

$$
\begin{gathered}
\mathrm{TI}_{\mathrm{L}}=\mathrm{TM}_{\mathrm{L}} \times\left(\mathrm{I}_{\mathrm{R}} / \mathrm{M}_{\mathrm{O}}\right) \\
=83 \times(51 / 51)
\end{gathered}
$$

Em seguida, ele perguntou se alguém entendera o significado do $I_{R}$. As alunas repetiram a informação que está no slide da apresentação oral. Joice argumentou:

Joice: Esses dados aí são tipo um censo que eles fazem, né?

Professor: Por que todo aquele lado direito da equação me dá uma boa previsão do que tá no lado esquerdo? [...] É importante ter uma previsão do que tá no lado esquerdo [...], que se eu souber que vai ter 83 no RS [...], isso representa

\footnotetext{
${ }^{11}$ BLACK; R. J.; BRAY, F.; FELAY; J.; PARKIN, D. M. Cancer Incidence and Mortality in the European Union: Cancer Registry data Estimates of Nation Incidence for 1990. European Journal of Câncer. 1997, 37(7): 1075-1107 (referência informada no slide 18 da apresentação oral).
} 
muito em termos de leito em hospitais, em termos de cirurgias [...] ou, às vezes, [...] atacar aquele problema em massa no RS pra tentar diminuir [...].

Joice tentou responder, associando-o com o censo, que é conhecido por ela. O professor buscou compreender o dado, não o aceitando como um modelo matemático pronto. Dando continuidade, ele explicou que poderiam ser outras fórmulas, como calcular a média aritmética dos últimos anos, mas que não seria razoável. Propôs o problema para toda a turma, formando um novo coletivo de seres-humanos-com-mídias. Essa situação se caracteriza de maneira diferente da situação do gráfico com escala logarítmica, pois, na anterior, ele sabia a resposta. Alguns alunos que estavam na platéia começaram a se manifestar.

Bianca: Do lado direito [...] é a tendência que tá acontecendo em todos os anos. Ali o $\mathrm{I}_{\mathrm{R}} / \mathrm{M}_{\mathrm{O}}$ é o fator presente, do que tá acontecendo agora, [...] é quanto cresceu de novos casos por quanto morreu. Então é uma tendência atual de todos os fatores que tão acontecendo, multiplicado pela tendência histórica que vem acontecendo em todos os anos. Isso vai te dar uma tendência do que vai acontecer na atualidade.

Júlia: Eu não entendi direito porque essa taxa de mortalidade é estimada pela série histórica. Como assim, como se eu continuasse a reta? Pego os anos anteriores ou...

Professor: Júlia, eu tô achando que essa série... taxa de mortalidade estimada pela série histórica é dizendo que se tá assim, vai acontecer isso (mostra que pode mudar o coeficiente angular da reta tangente ao gráfico, passando a ter valor menor do que zero).

[...]

Professor: Nota: esse aqui não é um modelo matemático extremamente complexo, mas nota o que passou aqui, eu agora já tô entendendo melhor do que [...] quando estava lendo este relatório. Mas ainda não tô bem [convencido]. Bianca fez uma comparação com o tema população, que deve ter lido em outras disciplinas do Curso de Ciências Biológicas.

Professor: Se eu tiver mais óbitos, por exemplo, do que casos novos, vamos supor que morreu mais gente e teve poucos casos novos, muita gente fez uma campanha de prevenção, aí quer dizer que minha estimativa, pro outro ano, de casos novos, reduz?

Leandro ${ }^{12}$ : Sim, a tendência é diminuir a taxa.

O professor ressaltou o momento do coletivo tentando investigar, salientando

\footnotetext{
${ }^{12}$ Primeiro autor do artigo.
} 
que isso é pesquisa e que, algo aparentemente simples, gerou muita reflexão. Outra aluna comentou:

Andréia: Eu acho que ainda não tá muito clara a ideia. Quando divide os casos novos, talvez você ache, não é isso, mas só pra dar uma ideia, talvez seja o número de casos vivos. Se você multiplica pela taxa de mortalidade, sei lá $20 \%$, é como se você tivesse tirado $20 \%$ dos vivos da taxa de incidência dos casos que não vão morrer. Se você tira os $20 \%$ mortos de $\left[\mathrm{I}_{\mathrm{R}} / \mathrm{M}_{\mathrm{O}}\right]$, acha o número de vivos, multiplica pela porcentagem da taxa de mortalidade,...

Professor: Tamos aqui agora com um produto de taxas e não como um número absoluto ali vezes outros. Tá me parecendo algo mais razoável.

No relatório escrito, as alunas escreveram: Obs: o grupo não conseguiu obter os dados referentes ao cálculo da metodologia descrita acima, apenas as taxas de incidência já calculadas e fornecidas pelo INCA (p. 4).

Podemos realizar diversas reflexões, desde a importância do professor no processo de modelagem, como já feito por diversos autores (e.g. BARBOSA, 2001), ou o papel da tecnologia na geração de conjecturas, conforme já feito em trabalhos do GPIMEM. Vamos nos concentrar, como propusemos, na interpretação destes dados prontos, ou de dados levantados neste novo campo, denominado Internet.

Nos excertos apresentados, notamos a presença de outros contextos vivenciados pelos alunos. Termos como censo e população, conhecidos por eles, foram empregados na tentativa de compreender o dado pronto. Notamos a relação da interpretação da informação presente no gráfico pictórico e da fórmula que foi usada para encontrar esse dado. Na apresentação oral, as alunas fizeram apenas a leitura dos dados (fórmula e gráfico) e não deram maiores explicações.

Notamos que as alunas buscaram incorporar a matemática, possivelmente por estarem sendo avaliadas por um professor desta disciplina, mas não conseguiram atender plenamente o interesse que elas acreditavam ser do professor, pois incorporaram um gráfico, mas não o compreendiam. Na apresentação oral, com o pouco tempo que dispunham para desenvolver o projeto de modelagem, não abordaram seus interesses com a profundidade que gostariam, pois uma aluna afirmou na entrevista que o grupo poderia ter abordado mais a parte biológica, elemento destacado desde a escolha do tema, como explicar os novos tratamentos. Assim, incorporar dados prontos pode ser sinônimo do não aprofundamento das ideias presentes no projeto de modelagem da forma 
como as alunas poderiam e gostariam de ter feito. Desta forma, como propõe Curcio (1987), as alunas podem realizar somente a leitura dos dados.

Com isso, o professor assumiu papel importante, pois ele solicitou que apresentassem um exemplo, utilizando a fórmula. Em seguida, o professor propôs uma interpretação qualitativa da fórmula, ou seja, ler entre os dados, que aqui tomou um significado diferente daquele proposto por Curcio (1987), já que o exemplo foi calculado a partir da fórmula, na tentativa de contribuir na sua compreensão. Ele convidou a plateia para compor o coletivo seres-humanoscom-mídias, para que pudessem pensar sobre a fórmula, e não apenas repeti-la e aceitá-la passivamente.

O professor criou condições para que pudessem compreender os possíveis significados dos dados prontos, pois não havia condições para tornálos compreensíveis. Com isso, o professor convidou os alunos a refletirem sobre o que Borba e Skovsmose (2001) nomeiam de ideologia da certeza, pois, muitas vezes, aceitamos dados prontos que envolvem modelos matemáticos devido ao status de verdade que possuem, e não adentramos no debate para compreender esses modelos, questioná-los. O gráfico e a fórmula, da forma como foram apresentados pelos estudantes, evidenciam o poder que a Matemática tem para formatar nossa vida em sociedade (BORBA; SKOVSMOSE, 2001).

Com os debates realizados após a apresentação oral do projeto Câncer de Próstata, dados prontos foram postos em discussão desafiando a ideologia da certeza. Nos excertos acima, discutia-se se os dados prontos faziam sentido, mesmo sendo eles compostos por gráficos e fórmulas, expressões oficiais da matemática.

No cenário apresentado, podemos destacar o engajamento dos alunos na tentativa de identificar relações importantes que não foram disponibilizadas e que complementariam a compreensão dos dados prontos, os quais parecem gerar o mesmo resultado que a coleta de dados em campo. Ou seja, parece que o virtual não se opõe ao real, como corroboram autores a exemplo de Bicudo e Rosa (2010). Esses autores, assim como Borba, Malheiros e Zulatto (2007), propõem que o mundo virtual já é parte do cotidiano de uma boa parte da população, sendo real e cotidiano para eles.

Parece que, para esses estudantes, os dados prontos são tão construídos por eles quanto os dados sobre o crescimento de sementes coletados ao longo de várias semanas, em um trabalho discutido há mais de uma década (BORBA; MENEGHETTI; HERMINI, 1999b). 


\section{Considerações Finais}

Borba (2009) sugere que a aceitação integral da Internet em sala de aula levaria a transformá-la, já que as questões que, em geral, são discutidas na sala de aula, não seriam mais problemas. Nesta perspectiva futurista, trabalhos de investigação abertos, conforme a tradição da modelagem, poderiam configurar uma das poucas alternativas pedagógicas. Independente de a Internet pertencer à sala de aula, de forma consistente, ou dela se dissolver na própria Internet, desnaturalizando a noção de que a sala de aula é o lócus central para a Educação, a discussão feita sobre dados prontos mostra que já há mudanças a serem feitas na matriz 1, apresentada anteriormente, em que se discute a interação entre TIC e Modelagem.

O quadro apresentado por Borba e Villarreal (2005), e refinado por Diniz (2007), terá que passar por profundas mudanças, não só para incorporar a Internet (em sua versão atual 2.0 ou 3.0), mas, também, porque parece que a Internet provoca mudanças nos objetivos, quando se propõe atividades de modelagem presentes no quadro, e discutidos também na segunda seção deste artigo. A linha referente a problemas aplicados no livro didático tradicional sumirá, visto que se a Internet for aceita, suas respostas estarão lá publicadas, ou serão facilmente encontradas nas redes sociais. Alternativamente, o grau de aceitação da Internet poderá se tornar um novo eixo, para uma matriz 3D. A possibilidade de se publicar os trabalhos na Web - como já acontece parcialmente em ambientes especializados, como o Centro Virtual de Modelagem (CVM) ${ }^{13}$, também poderá ser um novo vetor que gere novas combinações. Cremos que é cedo para a elaboração de tal quadro, mas novos trabalhos empíricos e reflexões, como feitas neste artigo, ajudarão neste objetivo.

O uso de blogs, de redes sociais como o Facebook $^{14}$ (a mais popular do Brasil, no momento) e a contínua transformação da Internet, com um suporte cada vez maior para vídeo, podem transformar a modelagem. Borba e Scucuglia (2009) apresentam possibilidades no projeto Performance Matemática Digital $(\mathrm{PMD})^{15}$, no qual vídeos sobre performances de estudantes e professores podem

\footnotetext{
${ }^{13} \mathrm{http} / / /$ tidia-ae.rc.unesp.br/cvm

${ }^{14} \mathrm{http}: / /$ facebook.com

${ }^{15} \mathrm{O}$ termo performance transcende o contexto de sua gênese em artes, que evidencia o corpo humano enquanto principal instrumento de desenho, pintura ou expressão artística. Performance Art pode ser concebida como uma região fronteiriça constituída por convergências entre expressões que envolvem e enfatizam a estética da comunicação-interação entre performers no espaço-tempo performático de criações e produções (teatrais, musicais, poéticas etc.) (http://en.wikipedia.org/ wiki/Performance_art).
} 
ser gerados em projetos que envolvam modelagem, como no estudo de modelos matemáticos sobre crescimento populacional. O GPIMEM já começa a investigar novas possibilidades de interação entre vídeos e educação matemática. Nesta modalidade, a Internet não estaria sendo só utilizada como meio de comunicação e interação, conforme a pesquisa de Malheiros (2008), mas também como meio para produção parcial da performance e de sua publicação. Boa parte dos estudos ainda são projetos exploratórios nos quais se veem novas possibilidades da Internet transformar práticas pedagógicas.

São possibilidades difusas, mas uma interpretação do modo como os dados prontos foram utilizados pelos alunos, sob a ótica da visão de tecnologia aqui apresentada (BORBA; VILARREAL, 2005; BORBA, 2009), sugere que a distinção entre dados prontos e dados gerados poderá se tornar cada vez mais tênue. Software que antes faziam simulações, agora se encontram impregnados em nichos da rede mundial de computadores. Compreender de forma mais profunda a relação entre dados prontos e dados gerados, no sentido tradicional, é uma necessidade que passará por entender como a própria noção de ser humano está se modificando a partir da transformação das mídias.

A noção de seres-humanos-com-mídias como agente do conhecimento se propõe a enfatizar a noção de que o conhecimento é produzido por coletivos de seres humanos e tecnologias que comunicam, mas, também, a enfatizar a proximidade, a sinergia, a impregnação de noções que, em vários dicionários de filosofia, estão quase como antônimos: ser humano e tecnologia!

Neste texto, utilizamos um artigo clássico em educação estatística (CURCIO, 1987), sobre a leitura e interpretação de gráficos estatísticos, para analisar a produção verbal e escrita dos alunos. Dessa forma, abandonamos a parte referente a níveis e buscamos valorizar o contexto da sala de aula, inclusive quando não se pratica a modelagem. Ao olharmos para outras partes da aula, e ao tomarmos uma visão de tecnologia que implica numa constante modificação do que significa o ser humano, buscamos incorporar a discussão sobre os aspectos socioculturais.

Seria interessante que outros grupos, além do GPIMEM, estivessem estudando a forma como a modelagem está sendo transformada pelas TIC em geral, e pela Internet, em particular, de forma que pudéssemos gerar um modelo que superasse, dialeticamente, a matriz apresentada em Borba e Villarreal (2005). 


\section{Agradecimentos}

Agradecemos os comentários e as sugestões feitas pelos membros do GPIMEM, a versões anteriores deste artigo: Aparecida Chiari, Silvana Santos, Adriana Richit, Ana Paula Malheiros, Claudinei Sant'Anna, Daise Lago, Débora Soares, Marcus Maltempi, Nilton Domingues, Ricardo Scucuglia e Sílvia Aimi. Agradecemos, também, os comentários feitos por Ivanise Arcanjo Diniz.

\section{Referências}

ARAÚJO, J. L. Cálculo, Tecnologias e Modelagem Matemática: as discussões dos alunos. 2002. 173f. Tese (Doutorado em Educação Matemática) - Instituto de Geociências e Ciências Exatas, Universidade Estadual Paulista, Rio Claro, 2002.

ARAÚJO; J. L.; BORBA, M. C. Construindo pesquisas coletivamente em Educação Matemática. In: BORBA, M. C.; ARAÚJO, J. L. (Orgs.). Pesquisa Qualitativa em Educação Matemática. Belo Horizonte: Autêntica, 2004, p. 25-45.

BARBOSA, J. C. Modelagem Matemática: concepções e experiências de futuros professores. 2001. 253f. Tese (Doutorado em Educação Matemática) - Instituto de Geociências e Ciências Exatas, Universidade Estadual Paulista, Rio Claro, 2001.

BICUDO, M. A. V.; ROSA, M. Realidade e Cibermundo: horizontes filosóficos e educacionais antevistos. Canoas: Editora Ulbra, 2010.

BLUM, W.; NISS, M. Applied mathematical problem solving, modelling, applications, and links to others subjects - state, trends and issues in mathematics instruction. Educational Studies in Mathematics, Dordrecht, v. 22, n. 1, p. 37-68, fev. 1991.

BOGDAN, R.; BIKLEN, S. Investigação Qualitativa em Educação: uma introdução à teoria e aos métodos. Porto: Porto Editora, 1994.

BORBA, M. C. Potential Scenarios for Internet Use in the Mathematics Classroom. Zentralblatt für Didaktik der Mathematik, Berlim, v. 41, n. 4, p. 453-465, ago. 2009.

BORBA, M. C.; MALHEIROS, A. P. S.; ZULATTO, R. B. A. Educação a Distância online. Belo Horizonte: Autêntica, 2007.

BORBA, M. C.; MENEGHETTI, R. C. G; HERMINI, H. A. Estabelecendo critérios para a avaliação do uso de Modelagem em sala de aula: estudo de um caso em um curso de Ciências Biológicas. In: FAINGUELERNT, E. K.; GOTTLIEB, F. C. (Orgs.). Calculadoras Gráficas e Educação Matemática. Rio de Janeiro: Ed. Art Bureau, 1999a. p. 95-113. 
BORBA, M. C., MENEGHETTI, R. C. G.; HERMINI, H. A. Modelagem, Calculadora Gráfica e Interdisciplinaridade na sala de aula de um curso de Ciências Biológicas. In: FAINGUELERNT, E. K.; GOTTLIEB, F. C. (Orgs.). Calculadoras Gráficas e Educação Matemática. Rio de Janeiro: Art Bureau, 1999b. p. 75-94.

BORBA, M. C.; PENTEADO, M. G. Informática e Educação Matemática. 3.ed. Belo Horizonte: Autêntica, 2007.

BORBA, M. C.; SCUCUGLIA, R. Modelagem e Performance Matemática Digital em Educação Matemática online. GONÇALVES, R. A.; OLIVEIRA, J. S.; RIBAS, M. A. C. (Orgs.). A Educação na Sociedade dos Meios Virtuais. Santa Maria: Centro Universitário Franciscano, 2009. p. 153-171.

BORBA, M. C.; SKOVSMOSE, O. A Ideologia da Certeza em Educação Matemática. Educação Matemática Crítica: a questão da democracia. Campinas: Papirus, 2001. p. 127-148.

BORBA, M. C.; VILLARREAL, M. E. Humans-with-media and Reorganization of Mathematical Thinking: Information and Communication Technologies, Modeling, Visualization and Experimentation. New York: Springer Science+Business Media, Inc., 2005.

CAMPOS, C. R.; WODEWOTZKI, M. L. L.; JACOBINI, O. R. Educação Estatística: teoria e prática em ambientes de modelagem matemática. Belo Horizonte: Autêntica, 2011.

CARVALHO, L. T. L.; MONTEIRO, C. E. F.; CAMPOS, T. M. M. Refletindo sobre a Interpretação de Gráficos como uma Atividade de Resolução de Problemas. In: LOPES, C. E.; COUTINHO, C. Q. S.; ALMOULOUD, S. A. (Orgs.). Estudos e Reflexões em Educação Estatística. Campinas: Mercado das Letras, 2010. p. 213-227.

CRESPO, A. A. Estatística Fácil. 17. ed. São Paulo: Saraiva, 2001.

CURCIO, F. Comprehension of mathematical relationship expressed in graphs. Journal for Research in Mathematics Education. Reston, v. 18, n. 5, p. 382-393, 1987.

DINIZ, L. N. O Papel das Tecnologias da Informação e Comunicação nos Projetos de Modelagem Matemática. 2007. 118f. Dissertação (Mestrado em Educação Matemática) - Instituto de Geociências e Ciências Exatas, Universidade Estadual Paulista, Rio Claro, 2007. Disponível em: <http://www.ufrb.edu.br/publica/components/com_mtree/ attachment.php?link_id=49\&cf_id=31>. Acesso em: 05 out. 2011. 
EDWARDS, D.; HAMSON, M. Guide to Mathematical Modelling. Boca Raton: CRC Press, 1990.

FERREIRA, C. R.; BURAK, D. Considerações Iniciais sobre um curso de Modelagem Matemática em Ambientes Virtuais. In: CONFERÊNCIA NACIONAL SOBRE MODELAGEM E EDUCAÇÃO MATEMÁTICA, 6., 2009, Londrina. Anais... Londrina: Universidade Estadual de Londrina. 2009. p. 1-13. 1 CD-ROM.

FERNANDES, J. A.; MORAIS, P. C. Leitura e Interpretação de Gráficos Estatísticos por Alunos do $9^{\circ}$ Ano de Escolaridade. Educação Matemática Pesquisa, São Paulo, v.13, n.1, p. 95-115, 2011. Disponível em: <http://revistas.pucsp.br/index.php/emp/ article/view/5282/4052>. Acesso em: 2 set. 2011.

GOMES, L. F.; CARVALHO, L. M. T. L.; MONTEIRO, C. E. F. Dificuldades de Estudantes em Atividades de Gráficos de Linhas. In: CONFERÊNCIA INTERAMERICANADE EDUCAÇÃO MATEMÁTICA, 13., 2011, Recife. Anais... Recife: Universidade Federal de Pernambuco. 2011. 1 CD-ROM. Disponível em: $<$ http:/ /www.cimm.ucr.ac.cr/ocs/index.php/xiii_ciaem/xiii_ciaem/paper/viewFile/2142/647>. Acesso em: 30 ago. 2011.

\section{HERMÍNIO, M. H. G. B. O Processo de Escolha dos Temas dos Projetos de}

Modelagem Matemática. 2009. 139f. Dissertação (Mestrado em Educação Matemática) - Instituto de Geociências e Ciências Exatas, Universidade Estadual Paulista, Rio Claro, 2009. Disponível em: <http://www.rc.unesp.br/gpimem/downloads/dissetacoes/ herminio_mhgb_me_rcla.pdf $>$. Acesso em: 17 set. 2011.

HERMÍNIO, M. H. G. B; BORBA, M. C. A Noção de Interesse em Projetos de Modelagem Matemática. Educação Matemática Pesquisa, São Paulo, v. 12, n. 1, p. 111127, 2010. Disponível em: <http://revistas.pucsp.br/index.php/emp/article/view/3283/ 2182>. Acesso em: 2 jul. 2011.

JAVARONI, S. L. Abordagem Geométrica: possibilidades para o ensino e aprendizagem de Introdução às Equações Diferenciais Ordinárias. 2007. 231f. Tese (Doutorado em Educação Matemática) - Instituto de Geociências e Ciências Exatas, Universidade Estadual Paulista, Rio Claro, 2007. Disponível em: <http:// www.rc.unesp.br/gpimem/downloads/teses/javaroni_tese.pdf>. Acesso em: 20 ago. 2011.

KALINKE, M. A. Internet na Educação: quando, como, onde e porquê. Curitiba: Editora Chain, 2003.

LÉVY, P. As Tecnologias da Inteligência: o futuro do pensamento na era da informática. São Paulo: Editora 34, 1993. 
LÉVY, P. Cibercultura. 2. ed. São Paulo: Editora 34, 2000.

MAGDALENA, B. C.; COSTA, I. E. T. Internet em sala de aula: com a palavra, os professores. Porto Alegre: Artmed, 2003.

\section{MALHEIROS, A. P. S. A Produção Matemática dos Alunos em um Ambiente de}

Modelagem. 2004. 194f. Dissertação (Mestrado em Educação Matemática) - Instituto de Geociências e Ciências Exatas, Universidade Estadual Paulista, Rio Claro, 2004.

MALHEIROS, A. P. S.; BORBA, M. C.; DINIZ, L. N. Doze Anos de Produção Matemática de Estudantes de Biologia em um Ambiente de Modelagem. In: CONFERÊNCIANACIONAL SOBRE MODELAGEM E EDUCAÇÃOMATEMÁTICA, 4., 2005, Feira de Santana. Anais... Feira de Santana: Universidade Estadual de Feira de Santana. 2005. p. 1-12. 1 CD-ROM.

MALHEIROS, A. P. S. Educação Matemática online: a elaboração de projetos de Modelagem. 2008. 187f. Tese (Doutorado em Educação Matemática) - Instituto de Geociências e Ciências Exatas, Universidade Estadual Paulista, Rio Claro, 2008. Disponível em: <http://www.rc.unesp.br/gpimem/downloads/teses/ tese_malheiros_2008.pdf >. Acesso em: 1 nov. 2011.

MONTEIRO, C. E. Investigando o Senso Crítico na Interpretação de Gráficos entre Professores em Formação Inicial. In: REUNIÃO ANUAL DAASSOCIAÇÃO NACIONAL DE PÓS-GRADUAÇÃO E PESQUISA EM EDUCAÇÃO, 29., 2006, Caxambu, MG. Anais... Caxambu, MG: s/i. 2006. Disponível em: <http:// www.anped.org.br/reunioes/29ra/trabalhos/trabalho/GT19-2366-Int.pdf >. Acesso em: 30 out. 2011.

SANTOS, F. V.; ALMEIDA, L. M. W. A Utilização do Computador pelos Estudantes em uma situação de Modelagem Matemática. In: CONFERÊNCIA NACIONAL SOBRE MODELAGEM E EDUCAÇÃO MATEMÁTICA, 5., 2007, Ouro Preto. Anais... Ouro Preto: Universidade Federal de Ouro Preto. 2007. 1 CD-ROM.

SILVA, M. J. F.; LEVY, L. F. Modelagem Matemática e Informática na Educação: desafios da Educação Matemática numa visão holística. In: CONFERÊNCIA NACIONAL SOBRE MODELAGEM EEDUCAÇÃO MATEMÁTICA, 6., 2009, Londrina. Anais... Londrina: Universidade Estadual de Londrina. 2009. 1 CD-ROM.

SMOLE, K. S.; DINIZ, M. I. (Orgs.). Ler, Escrever e Resolver Problemas: habilidades básicas para aprender matemática. Porto Alegre: Artmed, 2001. 
SOARES, D. S. Investigando Sistemas Dinâmicos em um Curso de Biologia. In: ENCONTRO NACIONAL DE EDUCAÇÃO MATEMÁTICA, 10., 2010, Salvador. Anais... Salvador: Universidade Católica do Salvador/Centro de Convenções da Bahia, 2010.p. 1-10. 1 CD-ROM.

STRECK, D. R.; REDIN, E.; ZITKOSKI, J. J. Dicionário Paulo Freire. Belo Horizonte: Autêntica, 2009.

TIKHOMIROV, O. K. The psychological consequences of computarization. In:

WERSTSCH, J. V. (Ed.) The concept of activity in soviet psychology. New York: M. E. Sharpe. Inc., 1981.p. 256-278.

VILLARREAL, M. E.; BORBA, M. C. Collectives of humans-with-media in mathematics education: notebooks, blackboards, calculators, computers and notebooks throughout 100 years of ICMI. Zentralblatt für Didaktik der Mathematik. Berlim, v. 42, n. 1, p. 49-62, Feb. 2010.

Submetido em Outubro de 2010. Aprovado em Março de 2012. 